\title{
Influential Impact of Fodder Cultivation on Livelihood Status of Farmers
}

\author{
Reeba Jacob ${ }^{1}$ and M. Asokhan ${ }^{2 *}$ \\ ${ }^{1}$ Department of Agricultural Extension and Rural Sociology, Tamil Nadu Agricultural \\ University, Coimbatore, India \\ ${ }^{2}$ Deputy Registrar (Affiliation), Tamil Nadu Agricultural University, Coimbatore, India \\ *Corresponding author
}

\begin{abstract}
A B S T R A C T
The demand of green fodder for livestock rearing has been increasing and livestock breeds of farmers require good quality fodder and feed in order to increase milk yield of exotic breed. The study was conducted in Kerala state of India and comprised of 242 farmers selected from three districts of the state. The impact of fodder cultivation was assessed on five levels viz. direct, social, economic, psychological and indirect impact. The study revealed that the highest percentage of farmers perceived fodder cultivation to have a medium level impact on their overall livelihood. In case of direct and social impact, more than 60.00 per cent of farmers had an increase in their dairy yield, returns and social status. Fodder cultivation has also influenced the economical and psychological dimensions of farmers by improving the income obtained from farming and boosting the confidence of farmer in fodder cultivation. The indirect impact of fodder was seen in health status of livestock and environmental aspect in the farm. The study was undertaken with an objective to assess the impact fodder cultivation on the various dimensions of livelihood status of farmers
\end{abstract}

\section{Introduction}

Green fodder and forage crops are one of the most important parts of sustainable agriculture for both animals and humans. Advantages of growing fodder crop is not just limited to being a feed for livestock but the grass root system improves the organic matter content of soil, improves the metabolism of animals, ensured year around production, reduced weed development and the root system of forage crops checks soil erosion. Animal nutrition plays a major role when it comes to dairy production and feed scarcity accounts for nearly half of all losses in Indian dairy production (Pratap and Jha, 2005). The choice of livestock is largely dependent on the availability of fodder in the locality. In order to keep high quality livestock breeds, a farmer requires better quality fodder and ration so as to increase the milk yield of exotic breed than the local breeds. The impact of fodder technology on livelihood of farmers will help in understanding the needed technology interventions in green fodder and helps in improving the overall productivity of farm 
and economy of the farmers and develop suitable livelihood strategies to support the survival of the small scale farmers in the country.

In India, it is estimated that the average cultivated area devoted to fodder production is around 4 to 5 per cent of the total cultivated area. The total area under cultivated fodders is 8.30 million hectares on individual crop basis (Bhagmal et al., 2011). Livestock provides livelihood for the marginal and small land holders in the country. The contribution of livestock towards National GDP is 4.11 per cent against total agriculture GDP of 25.60 per cent and provides a livelihood to about 20.50 million people in the country (GOI, 2018). Livestock sector will continue to flourish due to increased urbanization which in turn increases demand for milk and meat. The profitability depends largely on the marketing, feeding pattern and feed ration of the cattle unit because the milk yield and milk quality is influenced by the feed and fodder intake Kadam et al., (2017) reported that Hybrid Napier is resourceful forage grass due to its perennial nature, high yielding ability, nutritional quality, palatability, suitability for silage making and low oxalate content than any other grasses. The excess green fodder yield of hybrid Napier can be preserved as silage for mitigating the acute shortage of green fodder during lean season. It produces more nutritious fodder with good palatability, taste and succulence, which is relished by the animals. Hence, it fulfills the nutritional needs of the animals, reduces expenditure on feed procurement, increases milk productivity and hence, makes the dairy farming more feasible and profitable.

Green fodder plays a pivotal role in growth and health of livestock by providing nutrients in natural way to animals and thus cutting the cost of feed. Production time or duration of green fodder is short in almost all varieties and being a perennial crop farmer get fodder for year around and thus he will be able to cut the cost of feed. The reduction in purchase of cattle feed coupled with low maintenance cost of green fodder can ensure a higher benefit from fodder cultivation. Islam et al., (2017) mentioned in their study that cent per cent farmers of the study areas opined that cattle rearing increased dramatically due to fodder production. As green grasses are more conducive to milk production, it has a great demand to dairy cattle farmers. Almost all the farmers give positive consent in case of more milk production, increasing family income, more milk consumption by the family members and development cost increased (such as education, health, sanitation, housing, clothing and nutrition etc.) due to gain in more family income in household. There is an increasing trend in livestock population and fodder has now become an irreplaceable component of dairy sector. Therefore the present study was undertaken with the specific objective to find out the impact of fodder cultivation on the livelihood status of farmers.

\section{Materials and Methods}

\section{Study area}

The study was conducted in three districts of Kerala state with an area of 5600 hectares under fodder crops. Kerala which is the southernmost state of India has fourteen revenue districts which are grouped into three based on the geography if the state: Northern Kerala (Malabar region), Central Kerala (Cochin region) and Southern Kerala (Travancore region). Modern day districts which correspond to each region are Kasaragod, Kannur, Wayanad, Kozhikode and Malappuram in North Kerala; Palakkad, Ernakulam, Thrissur and Idukki in Central Kerala and South Kerala districts of Kottayam, Alappuzha, Pathanamthitta, 
Kollam and Thiruvananthapuram. From each region, district with highest area under green fodder cultivation was selected as per Agricultural Statistics (2016-17) published by Department of Economics and Statistics, Government of Kerala.

The selected districts were Wayanad from Northern Kerala, Palakkad from Central Kerala and Kottayam from Southern Kerala. From each district, two blocks with maximum area under green fodder were identified and selected as location of research. The identified blocks viz. Uzhavoor and Erattupetta from Kottayam, Attappady and Chittoor from Palakkad and Kalpetta and Mananthavady from Wayanad.

\section{Sample selection and sample procedure}

To finalize the sample for the study, Dairy Development Offices and Dairy Co-operative Societies were visited in all the three districts. With the help of the department officials and Dairy Co-operative Societies of the concerned block, details related to dairy farmers and fodder subsidy beneficiaries were collected. Dairy co-operative society with highest number of farmers were identified and sample size of 242 fodder farmers were finalized through Proportionate Random Sampling Technique for each blocks based on the number of beneficiaries. Sample distribution in study area is shown in Table 1 .

\section{Data Collection and analysis}

Field survey and interview method were followed to collect primary data from the respondents. Pilot survey in Trivandrum district of Kerala was conducted in order to develop a well-structured interview schedule with required modification before starting the primary data collection. National Dairy Development Board officials and office bearers of Dairy Co-operative Societies from selected villages were also contacted for strengthening the research. Online and offline print media were used for secondary data collection. The data collected from respondents, interview, discussions and observation were scored, process and were statistically analyzed using Statistical Package for Social Sciences (SPSS).

The impact of fodder farming was analyzed based on five different dimensions namely direct, social, economic, psychological and indirect impact. Major dimensions were divided into sub components for the study and the responses obtained from the farmers were recorded on a three point continuum. The responses were increased, no change and decreased with scores assigned as three, two and one respectively.

\section{Results and Discussion}

\section{Overall impact of fodder farming on livelihood status of farmers}

Livelihood can be defined as the means of attaining a way of life and securing the basic and primary necessities of life. Fodder cultivation has its direct and indirect effects on income and quality of farmer's life. An effort was undertaken to find out impact of fodder cultivation on various dimensions of livelihood of farmers based on survey and interview. The distribution of respondents according to the overall impact of fodder farming is presented in Table 2.

A perusal of Table 2 shows that the overall impact of fodder on livelihood status was medium (60.74\%) followed by high and low level with 22.73 per cent and 16.53 per cent respectively. Analysis of Table 2 shows the impact on livelihood at district level. The interesting fact regarding Palakkad district was that a 60.94 per cent of farmers belong to the high impact category which was different 
from the total population and the reason behind this might be the importance of agriculture and dairy sectors of Palakkad district. Respondents from Palakkad district showed that agriculture is their passion than a mere occupation and this had a greater effect on their livelihood. When it comes to Kottayam and Wayanad districts, impact of fodder on livelihood status was medium level followed by low and high impact levels. Data collection revealed that though farmers are cultivating fodder as a feed source for their livestock they never considered fodder to have an impact on their day to day life activities like other agricultural and horticultural crops. The direct and indirect impacts of fodder on livelihood are presented from Table 3 to Table 7 .

\section{Direct impact of fodder farming on livelihood of farmers}

The direct impact of fodder farming included returns, cost of cultivation, expenditure on cattle feed and dairy yield. Distribution of respondents based on the direct impact fodder cultivation has on livelihood status if farmers are given in Table 3 .

Table 3 shows that with respect to the direct impact, 61.57 per cent and 60.34 per cent of farmers reported that increase in dairy yield and returns respectively. With regard to the cost of cultivation and expenditure on cattle feed 54.13 per cent and 50.42 per cent of farmers reported that there was no change in both.

Fodder crops are considered to be a crop which requires low maintenance and this thought might have naturally led to the "no change' response category and a minimum ration of cattle feed is fed to the cattle on a regular basis and this might have led to 'no change' in cattle feed. However the increased dairy yield reported by the majority of respondents coupled with no change or decreased change in cost of cultivation and expenditure on cattle fee provided farmer with an increased returns. Therefore it can be inferred that fodder farming positively affects the dairy yield which increases the net income or returns.

\section{Social impact of fodder farming on livelihood status of farmers}

Social impact in this present study can be defined as the effect of green fodder and fodder technology on the social well-being of the farmers. Social impact has its effect on health, education, community cohesion and various forms of social capital. Social impact may also include the goods and services offered to the respondents. Distributions of respondents based on social impact of fodder farming on livelihood status of farmers are shown in Table 4.

Table 4 revealed that 60.33 per cent of farmers expressed that there has been an improvement in social status whereas 35.12 per cent of respondents did not find any change in their social status. About half of the respondents shared their opinion that there was an increased awareness when it comes to socioeconomic development programmes (57.02 $\%)$ and increased linkage with local institutions $(50.41 \%)$.

On further analysis of Table 4 it is clear that more than half of the respondents felt there was 'no change' when it comes to social dimensions such as their entrepreneurial qualities $(58.26 \%)$, contact with scientists $(53.31 \%)$ and planning in family maintenance $(50.00 \%)$. Coming to the social participation of the respondents 44.21 and 42.15 per cent of farmers did not have any change in cooperative society activities and participation in political processes respectively, whereas 36.78 and 35.54 per cent of farmers 
participated actively in activities of cooperative societies and political processes respectively. Government interventions, trainings, awareness campaigns, exhibitions and a timely visit from extension personnel would have increased the social impact and influence on livelihood.

\section{Economic impact of fodder farming on livelihood status of farmer}

Economic impact with relevance to this present study can be defined as the contribution of fodder technology towards farm productivity, farm income, farm development and security of farmers' livelihood in recent years. Distribution of fodder farmers according to the economic impact is represented in Table 5.

It was found from the study that fodder had an impact on the economic aspect of farmer to a certain extent. Little above half of the total respondents $(50.41 \%)$ mentioned that there was an increase in the income after fodder cultivation. Further analysis of the Table showed that 49.59 per cent of farmers have developed savings habit. It can be inferred that as income increases savings habit of the respondent also increased. There was an increase in strengthening of bunds in field $(59.92 \%)$, renovation of irrigation structure (48.76\%), livestock capital $(48.35 \%)$, farm power possession $(45.04 \%)$ and new business like stationery shops, rubber nurseries etc. were initiated by 40.08 per cent of farmers.

Regarding the other economic impacts, farmers reported that they did not face any change or 'no change' in their standard of living $(60.33 \%)$ followed by security for future life $(57.85 \%)$, material possession $(56.61 \%)$, purchase of vehicles for farm and household activities (55.79\%), income generating activity $(52.89 \%)$, land resources $(52.89 \%)$, shelter security $(51.24 \%)$, investment in shares (47.52 \%) and land reclamation $(43.80 \%)$. Respondents who opined that there was a decrease in their livelihood status as a result of fodder cultivation belonged in a range from 23.14 per cent in initiation of new business to seven per cent for development of savings habit.

\section{Psychological impact of fodder farming on livelihood status of farmer}

Psychological impact for the study can be defined as the direct and indirect effect caused on the behavioural realm of the farmer as a result of fodder farming practices or technology by the farmer. Distribution of fodder respondents based on the psychological impact fodder has on their livelihood is shown in Table 5.

Table 5 indicates the impact of fodder cultivation on the psychological aspect of farmers and the results suggests that more than three-fifth of the fodder farmers $(60.33$ $\%)$ was having increased confidence in fodder cultivation. On further analysis, 56.20 percent of the fodder farmers opined that there was an increase in the opportunity to know about development activities followed by 50.83 per cent of the fodder farmers had improved their health conditions. Regarding decision making ability of the fodder farmers 48.35 percent had strong decision making ability and the remaining 44.21 per cent and 7.44 per cent of the fodder farmers had 'no change' and weak decision making ability.

A perusal of Table 5 shows a significant percent of farmers did not perceive any change regarding their leadership skills (53.72 $\%)$, consultation by fellow farmers $(43.80 \%)$, improved health condition (38.84\%), opportunity to know about development activities (35.12\%) and confidence in fodder cultivation $(32.64 \%)$. 
Indirect impact of fodder farming on livelihood status of farmers

Indirect impact can be considered to be the unanticipated, secondary or the unfelt impact on the livelihood of farmers and environment as a result of fodder cultivation. The indirect impact on livelihood status of farmers due to fodder cultivation is given in Table 6 .

In the case if indirect impact, Table 6 shows that 61.16 per cent of the fodder farmers reported that the health condition of the livestock has improved followed by 28.93 per cent farmers who perceived that there is "no change' in the health condition of livestock and 9.92 per cent of farmers considering fodder to reduce the health condition of livestock. The reason behind this perception might be due to the inadequate supply of good quality fodder.

Table 6 further infers that in case of the soil fertility, 60.74 per cent of fodder farmers opined that fertility level has increased due to fodder cultivation followed by 24.79 per cent of respondents who perceived 'no change' in the soil fertility. As fodder requires less or no chemical inputs the soil fertility of farm is not inversely affected than other crops. This reduced application of chemical inputs maybe the reason why farmers consider fodder to increase or not affect soil fertility.

Table.1 Sample distribution in study areas

\begin{tabular}{|l|c|c|c|c|c|c|}
\hline \multicolumn{1}{|c|}{ District } & \multicolumn{2}{c|}{ Palakkad } & \multicolumn{2}{c|}{ Kottayam } & \multicolumn{2}{c|}{ Wayanad } \\
\hline Block & Chittur & Attappady & Uzhavoor & Erattupetta & Kalpetta & Mananthavady \\
\hline Sample size & 42 & 22 & 16 & 52 & 49 & 61 \\
\hline
\end{tabular}

Table.2 Overall impact of fodder farming on livelihood status of farmers

\begin{tabular}{|l|l|c|c|c|c|c|c|c|c|}
\hline S1. No & Category & \multicolumn{2}{c|}{$\begin{array}{c}\text { Palakkad } \\
(\mathrm{n}=64)\end{array}$} & \multicolumn{2}{c|}{$\begin{array}{c}\text { Kottayam } \\
(\mathrm{n}=68)\end{array}$} & \multicolumn{2}{c|}{$\begin{array}{c}\text { Wayanad } \\
(\mathrm{n}=110)\end{array}$} & \multicolumn{2}{|c|}{$\begin{array}{c}\text { Total } \\
(\mathrm{N}=242)\end{array}$} \\
\hline & & No & $\%$ & No & $\%$ & No & $\%$ & No & $\%$ \\
\hline $\mathbf{1}$ & Low & 1 & 1.56 & 11 & 16.17 & 28 & 25.45 & 40 & 16.53 \\
\hline $\mathbf{2}$ & Medium & 24 & 37.50 & 47 & 69.12 & 76 & 69.09 & 147 & 60.74 \\
\hline $\mathbf{3}$ & High & 39 & 60.94 & 10 & 14.71 & 6 & 5.56 & 55 & 22.73 \\
\hline
\end{tabular}

Table.3 Direct impact of fodder farming on livelihood status of farmers

\begin{tabular}{|c|l|c|c|c|c|c|c|}
\hline $\begin{array}{c}\text { SI. } \\
\text { No }\end{array}$ & \multicolumn{1}{|c|}{ Impact } & \multicolumn{2}{|c|}{ Decreased } & \multicolumn{2}{c|}{$\begin{array}{c}\text { No } \\
\text { Change }\end{array}$} & \multicolumn{2}{c|}{ Increased } \\
\hline I & Direct impact & No & $\%$ & No & $\%$ & No & $\%$ \\
\hline $\mathbf{1}$ & Returns & 25 & 10.33 & 71 & 29.33 & 146 & 60.34 \\
\hline $\mathbf{2}$ & Cost of cultivation & 45 & 18.60 & 131 & 54.13 & 66 & 27.27 \\
\hline $\mathbf{3}$ & Expenditure on cattle feed & 51 & 21.07 & 122 & 50.42 & 69 & 28.51 \\
\hline $\mathbf{4}$ & Dairy yield & 20 & 8.26 & 73 & 30.17 & 149 & 61.57 \\
\hline
\end{tabular}


Table.4 Social impact of fodder farming on livelihood status of farmers

\begin{tabular}{|l|l|c|c|c|c|c|c|}
\hline & Social Impact & \multicolumn{2}{|c|}{ Decreased } & \multicolumn{3}{|c|}{ No Change } & \multicolumn{2}{|c|}{ Increased } \\
\hline & & No & $\%$ & No & $\%$ & No & $\%$ \\
\hline $\mathbf{1}$ & Improvement in social status & 11 & 4.55 & 85 & 35.12 & 146 & 60.33 \\
\hline $\mathbf{2}$ & $\begin{array}{l}\text { Awareness about socio-economic } \\
\text { development programmes }\end{array}$ & 19 & 7.86 & 85 & 35.12 & 138 & 57.02 \\
\hline $\mathbf{3}$ & Better linkage with local institutions & 31 & 12.81 & 89 & 36.78 & 122 & 50.41 \\
\hline $\mathbf{4}$ & Better planning in family maintenance & 21 & 8.68 & 121 & 50.00 & 100 & 41.32 \\
\hline $\mathbf{5}$ & Contact with scientists & 21 & 8.68 & 129 & 53.31 & 92 & 38.01 \\
\hline $\mathbf{6}$ & Developed entrepreneurial qualities & 34 & 14.05 & 141 & 58.26 & 67 & 27.69 \\
\hline $\mathbf{7}$ & Active member in co-operative societies & 46 & 19.01 & 107 & 44.21 & 89 & 36.78 \\
\hline $\mathbf{8}$ & Participation in political processes & 54 & 22.31 & 102 & 42.15 & 86 & 35.54 \\
\hline
\end{tabular}

Table.5 Economic impact of fodder farming on livelihood status of farmers

\begin{tabular}{|c|l|c|c|c|c|c|c|}
\hline & Economic impact & \multicolumn{2}{|c|}{ Decreased } & \multicolumn{2}{|c|}{ No Change } & \multicolumn{2}{|c|}{ Increased } \\
\hline $\mathbf{1}$ & & No & $\%$ & No & $\%$ & No & $\%$ \\
\hline $\mathbf{2}$ & Improvement in income & 25 & 10.33 & 95 & 39.26 & 122 & 50.41 \\
\hline $\mathbf{3}$ & Engelopment of savings habit & 17 & 7.02 & 105 & 43.39 & 120 & 49.59 \\
\hline $\mathbf{4}$ & Improvement in standard of living & 30 & 12.40 & 128 & 52.89 & 84 & 34.71 \\
\hline $\mathbf{5}$ & Security for future life & 31 & 12.81 & 146 & 60.33 & 65 & 26.86 \\
\hline $\mathbf{6}$ & Material possession & 27 & 11.16 & 140 & 57.85 & 75 & 30.99 \\
\hline $\mathbf{7}$ & Farm power possession & 26 & 10.74 & 137 & 56.61 & 79 & 32.64 \\
\hline $\mathbf{8}$ & Livestock capital & 27 & 11.16 & 106 & 43.80 & 109 & 45.04 \\
\hline $\mathbf{9}$ & Purchased vehicles for farm and household & 29 & 11.98 & 135 & 55.79 & 78 & 32.23 \\
\hline $\mathbf{1 0}$ & Lactivities (Transportation) & & & & & & \\
\hline $\mathbf{1 1}$ & Invested in shares & 41 & 16.94 & 128 & 52.89 & 73 & 30.17 \\
\hline $\mathbf{1 2}$ & Shelter security & 49 & 20.25 & 115 & 47.52 & 78 & 32.23 \\
\hline $\mathbf{1 3}$ & Renovated irrigation structures & 37 & 15.29 & 124 & 51.24 & 81 & 33.47 \\
\hline $\mathbf{1 4}$ & Strengthened bunds & 35 & 14.88 & 88 & 36.36 & 117 & 48.76 \\
\hline $\mathbf{1 5}$ & Reclaimed land & 28 & 11.57 & 69 & 28.51 & 145 & 59.92 \\
\hline $\mathbf{1 6}$ & Initiated new business & 38 & 15.70 & 106 & 43.80 & 98 & 40.50 \\
\hline & & 56 & 23.14 & 89 & 36.78 & 97 & 40.08 \\
\hline
\end{tabular}


Table.6 Psychological impact of fodder farming on livelihood status of farmers

\begin{tabular}{|l|l|c|c|c|c|c|c|}
\hline & \multicolumn{1}{|c|}{ Psychological impact } & \multicolumn{3}{c|}{ Decreased } & \multicolumn{2}{c|}{ No Change } & \multicolumn{2}{c|}{ Increased } \\
\hline & & No & $\%$ & No & $\%$ & No & $\%$ \\
\hline $\mathbf{1}$ & Confidence in fodder cultivation & 17 & 7.02 & 79 & 32.64 & 146 & 60.33 \\
\hline $\mathbf{2}$ & $\begin{array}{l}\text { Opportunity to know about development } \\
\text { activities }\end{array}$ & 21 & 8.68 & 85 & 35.12 & 136 & 56.20 \\
\hline $\mathbf{3}$ & Consultation by fellow farmers & 27 & 11.16 & 106 & 43.80 & 109 & 45.04 \\
\hline $\mathbf{4}$ & Improved health conditions & 25 & 10.33 & 94 & 38.84 & 123 & 50.83 \\
\hline $\mathbf{5}$ & Increased leadership skills & 26 & 10.74 & 130 & 53.72 & 86 & 35.54 \\
\hline $\mathbf{6}$ & Strong decision making ability & 18 & 7.44 & 107 & 44.21 & 117 & 48.35 \\
\hline
\end{tabular}

Table.7 Indirect impact of fodder farming on livelihood status of farmers

\begin{tabular}{|c|l|c|c|c|c|c|c|}
\hline S.No. & Indirect impact & \multicolumn{3}{|c|}{ Decreased } & \multicolumn{2}{c|}{ No Change } & \multicolumn{2}{c|}{ Increased } \\
\cline { 3 - 8 } & & No & $\%$ & No & $\%$ & No & $\%$ \\
\hline $\mathbf{1}$ & Improved health condition of livestock & 24 & 9.92 & 70 & 28.93 & 148 & 61.16 \\
\hline $\mathbf{2}$ & Increased soil fertility & 35 & 14.46 & 60 & 24.79 & 147 & 60.74 \\
\hline $\mathbf{3}$ & Conservation of water & 19 & 7.85 & 67 & 27.69 & 156 & 64.46 \\
\hline $\mathbf{4}$ & Enhanced biodiversity & 22 & 9.09 & 47 & 19.42 & 173 & 71.49 \\
\hline
\end{tabular}

While considering the water conservation by fodder crop 64.46 per cent of farmers considered fodder cultivation to have an increased impact on water conservation whereas27.69 per cent and around seven per cent farmers consider fodder to have "no change' and decreased impact on water conservation respectively. It can be inferred that71.49 per cent of fodder farmers consider fodder cultivation to enhance the biodiversity of the farm; followed by 19.42 per cent farmers who perceived 'no change' in the biodiversity at field level and nine per cent of farmers with the opinion that biodiversity of the farm had decreased. This notion may be due to the reason that a large area of land is being left uncultivated for a short period of time so that the fodder crop regrows and cultivating other crops during this period can hinder the regrowth of fodder.

In conclusion dairy farming is undoubtedly a profitable enterprise in which fodder crops play a major role. The impact of fodder crop ranges from improving the dairy yield and nutritional quality of milk to the livelihood of farmers. Fodder crop helps in achieving the feed requirement of livestock, improve the health status of livestock, influence the social participation of the farmers, improve the income and savings habit and enhance environmental sustainability by improving soil fertility, biodiversity conservation and so on.

The study revealed that though farmers knew the importance of having dairy cum fodder farming but they were unaware about the impact fodder crop can have in their livelihood if they considered marketing of fodder. Government and Non-Government Organizations should take initiatives to help and promote fodder cultivation and an ensured market so that farmers can get an additional income from marketing of surplus fodder. 


\section{Acknowledgement}

I am grateful for the help rendered by Indian Council of Social Science Research in form of Centrally Administered Fellowship 20182019.

\section{References}

Government of Kerala (2017). Agricultural Statistics, Department of Economics and Statistics. Trivandrum. Govt. of Kerala.

Government of India (2019). Annual Report, Department of Animal Husbandry, Dairying and Fisheries, Ministry of Agriculture and Farmers Welfare, Govt. of India

Bhagmal, S. K. A., A. K. Roy, S. Ahmed and D. R. Malviya (2011). Forage crops and grasses. Handbook of Agriculture.
ICAR (6th revised edition), New Delhi: 1353-1417.

Islam, S.,J. Begum, N. Sarker and M. Khatun (2017). Economics of fodder production for dairying in selected areas of Bangladesh. Bangladesh Journal of Animal Science, 46(2): 140-149.

Kadam, S.,A. A. Kumar and M. Arif (2017). Hybrid Napier for Round the Year Quality Fodder Supply to the Dairy Industry-A Review. Int. J. Curr. Microbiol. App. Sci, 6(10): 47784783.

Pratap, B. and A. Jha (2005). Economic losses due to various constraints in dairy production in India. Indian Journal of Animal Sciences, 75(12): 1470-1475.

\section{How to cite this article:}

Reeba Jacob and Asokhan, M. 2020. Influential Impact of Fodder Cultivation on Livelihood Status of Farmers. Int.J.Curr.Microbiol.App.Sci. 9(04): 129-137.

doi: https://doi.org/10.20546/ijcmas.2020.904.017 